\title{
Faktor-Faktor Yang Berhubungan Dengan Pemanfaatan Pelayanan K4 Oleh Ibu Hamil Di Wilayah Kerja Puskesmas Kabupaten Sumba Timur Tahun
}

\author{
Kartini Pekabanda ${ }^{1}$, Sutopo Patria Jati ${ }^{2}$, Atik Mawarni ${ }^{2}$ \\ 1) Prodi Keperawatan Waingapu, Poltekkes Kemenkes, Kupang \\ Jl. Adam Malik No.126 Sumba Timur \\ 2) Fakultas Kesehatan Masyarakat, Universitas Diponegoro, Semarang
}

Title : Factors Associated With The

Utilization Of K4 By Pregnant Women In The Region Of Eastern Sumba District Helth Centers In 2014

\section{Abstrak}

Pada tahun 2011-2013 terjadi penurunan cakupan K4 di Kabupaten Sumba Timur dan hanya mencapai $44,7 \%$, jauh dari target $85 \%$. Hasil studi pendahuluan menunjukkan bahwa ibu hamil tidak mengetahui manfaat pelayanan K4 dan mempunyai kesulitan dalam akses pelayanan kesehatan. Penelitian ini bertujuan untuk mengetahui faktor-faktor yang berhubungan dengan pemanfaatan pelayanan K4 oleh ibu hamil.

Penelitian observasional analitik ini menggunakan metode survey dengan desain cross sectional. Subjek penelitian adalah 96 ibu hamil yang dipilih secara multistage random sampling pada tingkat Puskesmas dan Desa. Pengambilan data dilakukan dengan wawancara menggunakan kuesioner terstruktur. Analisis bivariat dengan uji Chi Square dan multivariat dengan regresi logistik.

Hasil penelitian menunjukkan $71,8 \%$ responden tidak memanfaatkan pelayanan $\mathrm{K} 4$, $66,7 \%$ pengetahuan kurang, $66,7 \%$ persepsi kurang terhadap pelayanan bidan, $52,1 \%$ tersedia sarana prasarana, $75,0 \%$ sulit untuk mencapai Puskesmas, 56,3\% tidak tersedia biaya, 65,6\% persepsi terhadap kebutuhan pelayanan K4 masih rendah. Ada hubungan positif antara pengetahuan $(p=0,004)$, persepsi terhadap pelayanan bidan $(\mathrm{p}=0,004)$, sarana prasarana $(0,444)$, kemudahan mencapai Puskesmas $(\mathrm{p}=0,001)$, ketersediaan biaya $(\mathrm{p}=0,006)$, persepsi terhadap kebutuhan $(p=0,001)$ dengan pemanfaatan pelayanan K4. Tidak ada hubungan antara ketersediaan sarana prasarana Puskemas dengan pemanfaatan pelayanan K4. Faktor-faktor yang berpengaruh bersama-sama terhadap pemanfaatan pelayanan K4 adalah kemudahan mencapai Puskesmas (Exp-
$\mathrm{B}=4,728, \quad \mathrm{p}=0,001)$ dan persepsi terhadap kebutuhan $($ Exp-B=4,177 p=0,001)

Akses dan persepsi kebutuhan merupakan dua faktor utama dalam pemanfaatan pelayanan K4 di Kabupaten Sumba Timur. Disarankan Dinas Kesehatan untuk membangun Poskesdes di setiap Desa, agar pelayanan K4 lebih dapat dijangkau oleh ibu hamil.

$\begin{array}{ll}\text { Kata kunci } & \text { : Pemanfaatan Pelayanan K4 } \\ \text { Kepustakaan } & : 90(1990-2013)\end{array}$

\section{Abstract}

In 2011-2013 there was decline coverage of $K 4$ in East Sumba regency and it was only reached $44.7 \%$, it was far from the target of $85 \%$. The results of a preliminary study showed that pregnant women do not know the benefits of $K 4$ and have difficulty in accessing health services. This study aims to analyze the factors that are associated with K4 service utilization by pregnant women.

This analytic observational study uses survey methods with a cross-sectional design. The Subjects of the study were 96 pregnant women were who were selected by multistage random sampling at the health center and village. Data were collected by interviews using a structured questionnaire. Bivariate analysis is tested by the chi square test and multivariate logistic regression.

The research results showed that $71.8 \%$ of respondents did not utilize K4, $66.7 \%$ was lack of knowledge, $66.7 \%$ was less perception of midwife services, $52,1 \%$ was available infrastructure, $75.0 \%$ was hard to reach health center, $56.3 \%$ did not have costs, $65.6 \%$ had low perception of $K 4$. There is a positive relationship between knowledge $(p=0.004)$, perceptions of midwifery care $(p=0.004)$, infrastructure $(0.444)$, ease of reaching health center $(p=0.001)$, the availability of cost $(p=0.006)$, perception of needs ( $p=0.001)$ with the use of K4. There is no relationship between the availability of 
infrastructure health centers with the use of K4. Factors that influence the utilization together with $K 4$ is easy to reach health center (Exp-B $=4.728$, $p=0.001)$ and perception of needs (Exp- $B=$ $4.177 p=0.001$ ).

Access and perception of needs are the two major factors in the use of K4 in East Sumba regency. It is suggested to the Department of Health to build a Poskesdes or village health post in each village, so that $K 4$ is more reachable by pregnant women.

Keywords:K4 Service Utilization

Bibliography: 90 (1990-2013)

\section{Pendahuluan}

Berdasarkan kesepakatan global (Millenium Development Goals/MDGS) pada tahun 2015 diharapkan Angka Kematian Ibu menurun sebesar tiga-perempatnya dalam kurun waktu 1990-2015 dan Angka Kematian Bayi dan Angka Kematian Balita menurun sebesar dua-pertiga dalam kurun waktu 19902015. Berdasarkan hal itu Indonesia mempunyai komitmen untuk menurunkan AKI menjadi 102 per 100.000 Kelahiran hidup, Angka Kematian Bayi dari 68 menjadi 23 per 1000 kelahiran hidup dan Angka Kematian Balita 97 menjadi 32 per 1000 kelahiran pada tahun 2015. ${ }^{12}$

Angka Kematian Ibu (AKI) di Propinsi Nusa Tenggara Timur Tahun 2012 adalah 306 per 100.000 kelahiran hidup. ${ }^{3}$ Di Kabupaten Sumba Timur Angka Kematian Ibu (AKI) tahun 2011 sebanyak 253 per $100.000 \mathrm{KH}$, tahun 2012 mengalami penurunan mejadi 108 per $100.000 \mathrm{KH}$, tahun 2013 mengalami kenaikan kembali menjadi 215 per $100.000 \mathrm{KH}^{4}{ }^{4}$ Jumlah kehamilan di Kabupaten Sumba Timur tahun 2011 sebayak 7.881 kehamilan, Tahun 2012 sebanyak 7.382 kehamilan dan Tahun 2013 sebayak 6.960 kehamilan. Cakupan persalinan oleh tenaga kesehatan di Kabupaten Sumba Timur, tahun 2011 sebanyak $81,0 \%$, tahun 2012 sebanyak $88,3 \%$ dan tahun 2013 sebanyak $90,2 \%{ }^{3}$

Di Indonesia cakupan K4 tahun 2013 adalah 90 \%. Di Propinsi Nusa Tenggara Timur cakupan K4 Tahun 2011 yaitu 65,7 \%, Tahun 2012 yaitu $67,0 \%$, dan Tahun 2013 yaitu $66,3 \% .^{3}$ Di Kabupaten Sumba Timur cakupan K4 tahun 2011 sebesar 44,7\%, tahun 2012 sebesar 43,4\% dan Tahun 2013 sebesar
42,4\%. Sedangkan target cakupan K4 ibu hamil (K4) Kabupaten Sumba Timur adalah $85 \%{ }^{34}$.

Setiap ibu hamil harus mempunyai akses terhadap petugas dan pelayanan kesehatan. Akses ternyata masih menjadi persoalan di Kabupaten Sumba Timur yang merupakan daerah tertinggal, perbatasan, pegunungan dan kepulauan. Hal tersebut antara lain disebabkan adanya keterbatasan infrastruktur dan transportasi yang masih sangat terbatas, kondisi geografis dan cuaca yang sulit, budaya yang tidak mendukung, tidak mempunyai biaya serta masih kurangnya tenaga kesehatan. ${ }^{5}$

Kabupaten Sumba timur merupakan salah satu kabupaten di NTT dengan kondisi geografis yang sulit dijangkau dimana permukaan tanah yang bergunung dan berbukit menyebabkan masyarakat sulit mengakses fasilitas kesehatan. Mengingat Kabupaten Sumba Timur merupakan salah satu Kabupaten dengan infra strukuktur yang belum memadai serta transportasi di daerah terpencil yang masih sangat terbatas, maka akan sulit seorang ibu hamil ke sarana fasilitas kesehatan terdekat karena jarak tempuh yang lama berjam-jam. ${ }^{5}$

Pemanfaatan pelayanan kesehatan adalah hasil dan proses pencarian pelayanan kesehatan oleh seseorang maupun kelompok. Pengetahuan tentang faktor yang mendorong individu membeli kesehatan merupakan informasi kunci untuk mempelajari utilisasi pelayanan kesehatan. Mengetahui faktorfaktor yang memengaruhi pemanfatan/ utilisasi. ${ }^{6}$

Kunjungan K4 adalah kontak ibu hamil yang keempat atau lebih dengan petugas kesehatan untuk mendapatkan pemeriksaan kehamilan dan pelayanan kesehatan pada trimester III, usia kehamilan 28 minggu. Dalam pengelolaan program KIA disepakati bahwa cakupan ibu hamil adalah cakupan kunjungan ibu hamil yang keempat (K4), yang dipakai sebagai indikator tingkat perlindungan ibu hamil. Angka cakupan K4 diperoleh dari jumlah $\mathrm{K} 4$ dalam 1 tahun dibagi jumlah ibu hamil di wilayah kerja dalam 1 tahun. ${ }^{7}$ Pelayanan K4 pada ibu hamil menggambarkan kuantitas pelayanan 
kesehatan ibu dan anak dalam suatu wilayah kerja. $^{8}$

Pemeriksaan K4 ibu hamil dimaksudkan agar ibu hamil memeriksakan kehamilannya secara teratur, agar dapat mengenali komplikasi akibat kehamilan, mengenali adanya letak janin dan presentasi serta bila terdapat risiko yang menyertai kehamilannya sehingga dapat memantapkan rencana persalinan secara tepat dan memadai. Bila terlambat dalam mendeteksi dan menangani keadaan yang mengancam kehidupan ibu dan janinnya maka meningkatkan angka kematian ibu. ${ }^{9}$

Setiap kehamilan dapat berkembang menjadi masalah atau komplikasi setiap saat sehingga sangat diperlukan pemantauan selama kehamilan. ${ }^{10}$ Pada awalnya, kehamilan yang diperkirakan normal dapat berkembang menjadi kehamilan pathologi. sehingga ibu hamil harus rutin untuk memeriksakan kehamilannya agar dapat deteksi dini jika ada komplikasi kehamilan. Selain itu ibu hamil juga harus mengetahui tentang tanda bahaya kehamilan. Jika ibu mengetahui tentang tanda bahaya kehamilan, ibu akan selalu waspada dan berhati-hati dengan cara selalu rutin memeriksakan kehamilannya. ${ }^{11}$

Apabila ibu hamil tidak melakukan pemeriksaan kehamilan secara rutin, maka tidak akan diketahui apakah kehamilannya berjalan dengan baik atau mengalami keadaan risiko tinggi dan komplikasi obstetri yang dapat membahayakan kehidupan ibu dan janinnya. Dan dapat menyebabkan morbiditas dan mortalitas yang tinggi. ${ }^{9}$

Pemeriksaan kehamilan sesuai standar (4 kali) sangat mempengaruhi kesehatan ibu hamil dan janinya. Pemeriksaan kehamilan pada trimester ke 3 (>28 minggu) sangat penting karena pada trimester 3 bidan melakukan palpasi abdomen untuk mendeteksi adanya kehamilan ganda, kelainan letak, atau kondisi lain yang memerlukan kelahiran di Rumah Sakit. ${ }^{12}$ Angka kematian ibu maternal dapat diturunkan sampai 20\% hanya dengan pelayanan kesehatan dasar seperti pelayanan kunjungan antenatal secara lengkap dari K1 sampai K4. ${ }^{13}$

Berdasarkan hasil wawancara awal yang dilakukan peneliti kepada 10 orang ibu hamil diperoleh bahwa, mereka tidak melakukan pemeriksaan kehamilan K4 dengan alasan sebanyak 8 orang mengatakan tidak mengetahuI manfaat dari pemeriksaan kehamilan K4, 2 orang ibu hamil mengatakan tahu tentang manfaat pemeriksaan K4 tetapi ibu hamil lebih memilih bekerja diladang dengan alasan kehamilan mereka baik-baik saja tanpa harus memeriksakan ke fasilitas kesehatan, sebanyak 6 orang menyatakan karena tempat tinggalnya jauh dan di daerahnya tidak dilalui kendaraan angkutan umum, jika memanfaatkan jasa ojek maka biaya transportasi yang harus dikeluarkan cukup besar sehingga hal ini juga menjadi pertimbangan untuk memanfaatkan pelayanan K4 di Puskesmas. 4 orang ibu hamil mengatakan periksa ke Puskesmas kalau ada keluhan saja, 2 orang ibu hamil mengatakan bidan kurang ramah dan pelayanan bidan kurang memuaskan, 2 ibu hamil mengatakan bidan sering membedakan status sosial masyarakat. 4 ibu mengatakan tidak membutuhkan pemeriksaan K4 karna merasa sehat-sehat saja.

Di Puskesmas Waingapu pada tahun 2013, jumlah ibu hamil yang seharusnya memanfaatkan pelayanan K4 berjumlah 358 orang, yang menggunakan sebanyak 165 orang $(46,1 \%)$. Puskesmas Kambaniru yang seharusnya memanfaatkan pelayanan K4 berjumlah 128 orang, yang menggunakan sebanyak 71 orang $(56 \%)$. Puskesmas Kawangu jumlah ibu hamil yang seharusnya memanfaatkan pelayanan K4 berjumlah 95 orang, yang menggunakan sebanyak 35 orang (36,8\%). Puskesmas Melolo yang seharusnya memanfaatkan pelayanan K4 berjumlah 116 orang, yang menggunakan sebanyak 35 orang (30\%), Puskesmas Lewa yang seharusnya memanfaatkan pelayanan K4 berjumlah 112 orang, yang menggunakan sebanyak 26 orang ( 23,5\%). Dari gambaran tersebut, menunjukkan bahwa tidak semua ibu hamil memanfaatkan pelayanan K4 di Puskesmas.

Kunjungan pemeriksaan kehamilan merupakan salah satu bentuk pemafaatan pelayanan K4. Menurut Andersen ${ }^{8}$ beberapa faktor yang mempengaruhi pemanfaatan pelayanan kesehatan adalah faktor need (kebutuhan), faktor predisposing seperti keadaan demografi, keadaan sosial, sikap dan kepercayaan, serta faktor enabling seperti 
pendapatan keluarga, ketersediaan dan keterjangkauan pelayanan baik dari segi harga/biaya pelayanan, jarak dan waktu pelayanan. ${ }^{14}$

Hasil studi pendahuluan di Kabupaten Sumba Timur menunjukkan bahwa masih rendahnya pemanfaatan pelayanan $\mathrm{K} 4$ oleh ibu hamil. Berdasarkan hal tersebut, maka perlu dilakukan pengkajian terhadap berbagai masalah yang dihadapi oleh ibu hamil di wilayah kerja Puskesmas Kabupaten Sumba Timur dalam hal mengakses dan memanfaatkan pelayanan pemeriksaan kehamilan K4. Untuk itu akan dilakukan penelitian tentang faktor-faktor yang berhubungan dengan pemanfaatan pelayanan K4 oleh ibu hamil di wilayah kerja Puskesmas Kabupaten Sumba Timur.

\section{Metode Penelitian}

Jenis penelitian ini merupakan penelitian analitik observasional yang bertujuan untuk mengetahui ada tidaknya hubungan tentang pengetahuan, persepsi terhadap pelayanan bidan, ketersediaan fasilitas puskesmas, kemudahan mencapai puskesmas, ketersedian biaya, persepsi terhadap kebutuhan dengan pemanfaatan pelayanan kunjungan keempat. Penelitian bersifat kuantitatif yaitu penelitian dengan menggunakan analisis uji hubungan antara variabel bebas dan variabel terikat. ${ }^{15}$ Pendekatan waktu untuk pengumpulan data digunakan pendekatan cross sectional. Pengumpulan data menggunakan data sekunder dan data primer menggunakan kuesioner terstruktur. Sampel pada penelitian ini berjumlah 96 responden, dengan cara multistage random sampling, pengambilan sampel dilakukan di desa yang berada pada 5 wilayah kerja Puskesmas Kabupaten Sumba Timur. Analisis bivariat menggunakan analisis tabulasi silang (crosstab) dan analisis chi-square, dan analisis multivariat dengan uji statistik regresi logistik berganda. ${ }^{16}$

\section{Hasil}

Karakteristik Responden

Pada penelitian ini sebagian besar responden berpendidikan SD (28.1\%) dan yang berpendidikan DIII sebesar $11.5 \%$, responden yang tidak bekerja sebesar 31.3\% dan responden yang bekerja sebesar $68.7 \%$, sebagian besar responden berpendapatan rendah sebesar $65.5 \%$ dan responden berpendapatan tinggi sebesar $36.5 \%$, responden yang memiliki jumlah anggota keluarga lebih dari 4 sebesar $67.7 \%$ dan yang memiliki anggota keluarga kurang dari 4 sebesar $32.3 \%$, rata-rata umur ibu 31 tahun dengan standar deviasi \pm 6 tahun dan sebagian besar kehamilanya tidak beresiko tinggi $59,4 \%$.

\section{Deskripsi Analisis Univariat}

Tabel 1. menunjukkan bahwa sebagian besar responden $71,8 \%$ tidak memanfaatkan pelayanan $\mathrm{K} 4$, sebagian besar responden memiliki pengetahuan kurang sebesar $66,7 \%$, sebagian besar responden mempersepsikan pelayanan bidan kurang $61,5 \%$, sebagian besar sarana prasarana tersedia $52,1 \%$, sebagian besar responden sulit untuk mencapai Puskesmas 75,0\%, sebagian besar responden yang tidak tersedia biaya terkait dengan pemanfaatan K4 sebesar 56,3\%, sebagian besar persepsi responden terhadap kebutuhan menunjukkan bahwa $65,6 \%$ mempersepsikan kebutuhan terhadap pelayanan K4 masih rendah.

\section{Analisis Bivariat}

Tabel 2. menunjukkan bahwa variabel pengetahuan, persepsi terhadap pelayanan bidan, kemudahan mencapai Puskesmas, ketersediaan biaya, persepsi terhadap kebutuhan berhubungan dengan variabel pemanfaatan pelayanan $\mathrm{K} 4$ dan variabel yang tidak berhubungan sarana prasarana Puskesmas dengan variabel pemanfaatan pelayanan $\mathrm{K} 4$.

\section{Analisis Multivariat}

Analisis multivariat dengan menggunakan uji regersi logistik berganda dengan metode enter. Analisis multivariat dilakukan dengan beberapa tahapan. Semua variabel telah di uji bivariat dan memenuhi nilai $\mathrm{p} \leq 0,25$ maka semua variabel tersebut dimasukkan untuk dianalisis multivariat dan dikeluarkan satu persatu dengan nilai $\mathrm{p}$ yang paling besar dan tidak mengurangi nilai $\mathrm{R}^{2}>10 \%$. Jika mengurangi $\mathrm{R}^{2}>10 \%$ maka variabel tersebut tetap dipertahankan untuk dilanjutkan dalam analisis multivariat. Setelah dilakukan analisis diperoleh hasil sebagaimana disajikan pada Tabel 3 : 
Tabel 3. menunjukkan variabel yang memiliki nilai signifikansi $\mathrm{p}<0,05$ adalah variabel kemudahan mencapai Puskesmas (pvalue 0,002) dan variabel persepsi terhadap kebutuhan (p-value 0,003). Hal ini menunjukkan dari semua variabel yang diuji ternyata hanya dua variabel yang berpengaruh terhadap pemanfaatan pelayanan K4 yaitu kemudahan mencapai Puskesmas dan persepsi terhadap kebutuhan.

\section{Pembahasan}

Hasil uji Chi Square kemudahan mencapai Puskesmas dan pemanfaatan pelayanan $\mathrm{K} 4$ menunjukkan $\mathrm{X}^{2}=8,344$ dan nilai $p=0,001(p<0,05)$, maka Ho ditolak dan Ha diterima. Menurut Zeithaml, dkk ${ }^{17}$ salah satu parameter konsep kepuasan pelanggan adalah lokasi yang mudah dijangkau. Hal ini sesuai dengan pendapat Andersen ${ }^{8}$ pemanfaatan pelayanan kesehatan dipengaruhi oleh sumber daya masyarakat salah satunya adalah lokasi sarana kesehatan.

Salah satu faktor pendukung utilisasi pelayanan kesehatan dipengaruhi oleh faktor kemudahan mencapai fasilitas kesehatan. ${ }^{14}$ Kemudahan mencapai Puskesmas adalah seberapa mudah ibu hamil dalam menjangkau Puskesmas. Kemudahan mencapai Puskesmas ini diukur dengan seberapa jauh jarak rumah pasien dengan Puskesmas dan alat trasportasi yang digunakan menuju Puskesmas.

Menurut Prakash Gupta, salah satu hal yang mempengaruhi seseorang untuk berperilaku adalah kemudahan akses dalam mencapai lokasi. Dalam teori RCSM (Retail Customer Satisfaction Model), diungkapkan bahwa hal yang paling penting dalam keberhasilan sebuah bisnis adalah keberadaannya di lokasi yang strategis dimana pasien dapat mencapainya. ${ }^{17}$ Menurut Levy dan Weitz, beberapa faktor yang mempengaruhi daya tarik suatu lokasi adalah aksesibilitas. Aksesibilitas lokasi adalah suatu kemudahan dimana pasien dapat datang dan pergi tanpa harus menunggu lama karena adanya kendaraaan umum yang melintasi sebuah Puskesmas. ${ }^{18}$
Hasil uji Chi Square antara persepsi kebutuhan dan pemanfaatan pelayana K4 menunjukkan $\mathrm{X}^{2}=10,352$ dan nilai $\mathrm{p}=0,001$ $(\mathrm{p}<0,05)$, maka Ho ditolak dan Ha diterima. Hasil ini memilki makna ada hubungan yang signifikan antara persepsi terhadap kebutuhan dengan pemanfaatan pelayanan $\mathrm{K} 4$.

Menurut Andersen, faktor kebutuhan berperan lebih besar dibandingkan faktor lain, dimana persepsi terhadap suatu fasilitas kesehatan yang memiliki manfaat lebih besar sebagai upaya untuk mengobati penyakit atau mencegah timbulnya suatu penyakit.

Kebutuhan pelayanan kesehatan bersifat mendasar yang sesuai dengan keadaan riil masyarakat. Sedangkan permintaan pelayanan kesehatan terkait unsur preferensi yang dapat dipengaruhi oleh sosial budaya. Idealnya kebutuhan dan permintaan adalah sama atau berupa suatu keadaan yang identik. Permintaan akan tampak kalau masyarakat sakit dan mencari pengobatan atau informasi dan memanfaatkan pelayanan kesehatan yang tersedia. Permintaan dapat dilihat dari angka kunjungan pasien ke tempat pelayanan kesehatan.

Dari semua variabel bebas yang dianalisis secara bersama-sama, dapat dilihat dari nilai Exp(B), variabel kemudahan mencapai Puskesmas mempunyai nilai $\operatorname{Exp(B)}$ sebesar 4,782, menunjukkan jika mudah mencapai Puskesmas maka akan meningkatkan pemanfaatan pelayan $\mathrm{K} 4$ oleh ibu hamil sebesar 4,7 kali lebih besar dari pada ibu yang sulit mencapai Puskesma. Persepsi kebutuhan mempunyai nilai $\operatorname{EXP(B)~sebesar~4,177,~}$ menunjukkan bahwa semakin tinggi persepsi terhadap kebutuhan, maka akan meningkatkan pemanfaatan pelayanan $\mathrm{K} 4$ oleh ibu hamil sebesar 4,177 kali lebih besar dari pada ibu hamil yang mempersepsikan kebutuhan rendah. Nilai $\mathrm{R}^{2}$ diperoleh $28,0 \%$ yang artinya variasi variabel Pemanfaatan pelayan $\mathrm{K} 4$ sebesar $28,0 \%$ disumbang oleh variabel kemudahan mencapai Puskesmas dan persepsi terhadap kebutuhan. Hal ini menunjukkan bahwa untuk meningkatkan pemanfaatan pelayanan K4 oleh ibu hamil, maka perlu adanya kemudahan mencapai Puskesmas dan kebutuhan individu terhadap pelayanan K4. 
Tabel 1. Kategori Pemanfaatan K4, Pengetahuan, Persepsi terhadap Pelayanan Bidan, Sarana Prasarana, Kemudahan mencapai Puskesmas, Ketersediaan Biaya, dan Persepsi terhadap Kebutuhan

\begin{tabular}{|c|c|c|c|}
\hline No & Variabel & $\mathbf{F}$ & $\%$ \\
\hline \multirow[t]{3}{*}{1} & Pemanfaatan Pelayanan K4 & & \\
\hline & Tidak memanfaatkan & 69 & 71,8 \\
\hline & Memanfaatkan & 27 & 28,2 \\
\hline \multirow[t]{3}{*}{2} & Pengetahuan & & \\
\hline & a. Kurang & 64 & 66,7 \\
\hline & b. Baik & 32 & 33,3 \\
\hline \multirow[t]{3}{*}{3} & Persepsi terhadap Pelayanan Bidan & & \\
\hline & a. Kurang & 59 & 61,5 \\
\hline & b. Baik & 37 & 38,5 \\
\hline \multirow[t]{3}{*}{4} & Sarana Prasarana & & \\
\hline & a. Tidak tersedia & 46 & 47,9 \\
\hline & b. Tersedia & 50 & 52,1 \\
\hline \multirow[t]{3}{*}{5} & Kemudahan mencapai Puskesmas & & \\
\hline & a. Sulit & 72 & 75,0 \\
\hline & b. Mudah & 24 & 25,0 \\
\hline \multirow[t]{3}{*}{6} & Ketersediaan Biaya & & \\
\hline & a. Tidak tersedia & 54 & 56,3 \\
\hline & b. Tersedia & 42 & 43,8 \\
\hline \multirow[t]{3}{*}{7} & Persepsi terhadap Kebutuhan & & \\
\hline & c. Rendah & 63 & 65,6 \\
\hline & d. Tinggi & 33 & 34,4 \\
\hline
\end{tabular}

Tabel 2. Faktor-faktor yang Berhubungan dengan Pemanfaatan Pelayanan K4 oleh Ibu Hamil di Wilayah Kerja Puskesmas Kabupaten Sumba Timur

\begin{tabular}{|c|c|c|c|c|c|c|c|c|}
\hline & & \multicolumn{4}{|c|}{ Pemanfatan pelayanan $\mathrm{K} 4$} & \multirow{2}{*}{\multicolumn{2}{|c|}{ Total }} & \\
\hline & & & ggi & & dah & & & \\
\hline & & $\mathbf{n}$ & $\%$ & $\mathbf{n}$ & $\%$ & $\mathbf{N}$ & $\%$ & \\
\hline \multirow[t]{3}{*}{1} & Pengetahuan & & & & & & & \\
\hline & Kurang & 53 & $82,8 \%$ & 11 & $17,2 \%$ & 64 & $100 \%$ & \multirow{2}{*}{$\begin{array}{c}X^{2}=11,755 ; \\
p=0,004\end{array}$} \\
\hline & Baik & 10 & $31,3 \%$ & 22 & $68,8 \%$ & 32 & $100 \%$ & \\
\hline \multirow[t]{4}{*}{2} & Persepsi terhadap & & & & & & & \\
\hline & Pelayanan Bidan & & & & & & & \\
\hline & Kurang & 45 & $70,3 \%$ & 19 & $29,7 \%$ & 64 & $100 \%$ & \multirow{3}{*}{$\begin{array}{l}X^{2}=11,755 \\
p=0,004\end{array}$} \\
\hline & Baik & 10 & $31,3 \%$ & 22 & $68,8 \%$ & 32 & $100 \%$ & \\
\hline \multirow[t]{3}{*}{3} & Sarana Prasarana & & & & & & & \\
\hline & Tidak tersedia & 24 & $52,2 \%$ & 22 & $47,8 \%$ & 46 & $100 \%$ & \multirow{3}{*}{$\begin{array}{l}X 2=0,586 \\
p=0,444\end{array}$} \\
\hline & Tersedia & 31 & $62,0 \%$ & 19 & $38,0 \%$ & 50 & $100 \%$ & \\
\hline \multirow[t]{3}{*}{4} & $\begin{array}{l}\text { Kemudahan } \\
\text { mencapai Puskesmas }\end{array}$ & & & & & & & \\
\hline & Sulit & 35 & $72,9 \%$ & 13 & $27,1 \%$ & 48 & $100 \%$ & \multirow{3}{*}{$\begin{array}{l}X^{2}=8,344 \\
p=0,001\end{array}$} \\
\hline & Mudah & 20 & $41,7 \%$ & 28 & $58,3 \%$ & 48 & $100 \%$ & \\
\hline \multirow[t]{3}{*}{5} & Ketersediaan Biaya & & & & & & & \\
\hline & Tidak tersedia & 38 & $70,4 \%$ & 16 & $29,6 \%$ & 54 & $100 \%$ & \multirow{3}{*}{$\begin{array}{l}X^{2}=7,450 \\
p=0,006\end{array}$} \\
\hline & Tersedia & 17 & $40,5 \%$ & 25 & $59,5 \%$ & 42 & $100 \%$ & \\
\hline \multirow[t]{4}{*}{6} & Persepsi terhadap & & & & & & & \\
\hline & Kebutuhan & & & & & & & \\
\hline & Rendah & 44 & $69,8 \%$ & 19 & $30,2 \%$ & 63 & $100 \%$ & \multirow{2}{*}{$\begin{array}{l}X^{2}=10,352 ; \\
p=0,001\end{array}$} \\
\hline & Tinggi & 11 & $33,3 \%$ & 22 & $66,7 \%$ & 33 & $100 \%$ & \\
\hline
\end{tabular}


Tabel 3. Hasil Analisis Multivariat menggunakan Uji Regresi Logistik dengan menggunakan Metode Enter

\begin{tabular}{|c|c|c|c|c|c|c|c|c|}
\hline & B & S.E & Wald & Df & Sig. & $\operatorname{Exp}(B)$ & \multicolumn{2}{|c|}{$\begin{array}{l}95 \% \text { C.I For } \\
\operatorname{Exp}(\mathrm{B})\end{array}$} \\
\hline & 1554 & 494 & 9898 & 1 & 002 & 4728 & Lower & $\begin{array}{l}\text { Upper } \\
12445\end{array}$ \\
\hline $\begin{array}{l}\text { mencapai } \\
\text { puskesmas }\end{array}$ & & & & & & & & \\
\hline Kebutuhan & 1.430 & .489 & 8.561 & 1 & .003 & 4.177 & 1.603 & 10.882 \\
\hline
\end{tabular}

\section{Simpulan}

1. Tingkat pendidikan responden masih rendah yaitu tidak sekolah $(25 \%)$ dan tamat SD $(28,1 \%)$. Sebagian besar responden tidak bekerja $(68,7 \%)$. Pendapatan responden sebagian besar berpendapatan rendah $(65,5 \%)$. Responden sebagian besar memiliki jumlah anggota keluarga lebih dari $4(67,7 \%)$. Rata-rata umur responden 31,0 tahun dengan standar deviasi 6 tahun.

2. Sebagian besar responden $(71,8 \%)$ tidak memanfaatkan pelayanan K4. Sebagian besar responden $(66,7 \%)$ mempunyai tingkat pengetahuan kurang tentang pelayanan $\mathrm{K} 4$. Sebagian besar responden (61,5\%) mempunyai persepsi pelayanan bidan yang kurang. Sebagian besar responden (52,1\%) menyatakan sarana prasarana Puskesmas baik dan tersedia. Sebagian besar responden sulit untuk mencapai Puskesmas (75,0\%). Sebagian besar responden (56,3\%) tidak mempunyai biaya untuk pemanfaatan pelayanan K4. Sebagian besar responden $(65,6 \%)$ mempersepsikan kebutuhan terhadap pelayanan $\mathrm{K} 4$ masih rendah.

3. Ada hubungan antara pengetahuan $(p=0,004)$, persepsi terhadap pelayanan bidan $(\mathrm{p}=0,004)$, ketersediaan biaya $(p=006)$, kemudahan mencapai Puskesmas $(p=0,001)$, persepsi terhadap kebutuhan $(\mathrm{p}=0,001)$ dengan pemanfaatan pelayanan $\mathrm{K} 4$ oleh ibu hamil di Kabupaten Sumba Timur.

4. Tidak ada hubungan antara ketersediaan sarana-prasarana Puskesmas $\quad(p=0,444)$ dengan pemanfaatan pelayanan $\mathrm{K} 4$ oleh ibu hamil di Kabupaten Sumba Timur.

\section{Daftar Pustaka}

1. Departeman Kesehatan Republik Indonesia. Pedoman Pemantaun Wilayah
Setempat Kesehatan Ibu dan Anak (PWSKIA). Jakarta. 2009.

2. Departeman Kesehatan Republik Indonesia. Panduan Pelaksanaan Strategi Making Pregnancy Safer dan Child Survival. Jakarta. 2008.

3. Dinas Kesehatan Propinsi NTT. Profil Dinas Kesehatan Propinsi Nusa Tenggara Timur. Kupang. 2010-2012.

4. Dinas Kesehatan Kabupaten Sumba Timur NTT. Laporan Tahunan Kegiatan Program Kesehatan Ibu Tahun 20112013. Waingapu. 2013.

5. Dinas Kesehatan Propinsi Nusa Tenggara Timur. Pedoman Prototype Puskesmas Revolusi KIA dan Rumah Tunggu Propinsi Nusa Tenggara. 2012.

6. Ilyas Yaslis. Kiat Sukses Manajemen Kinerja. Jakarta. : PT Gramedia Pustaka Utama; 2003.

7. Rochjati P. Skrining Antenatal Pada Ibu Hamil. Surabaya: Airlangga Universitas Press; 2005.

8. Departeman Kesehatan Republik Indonesia. Rencana Strategis Departemen Kesehatan. Jakarta: Depkes RI; 2005.

9. Saifudin AB. Buku Panduan Praktis Pelayanan Kesehatan Maternal Neonatal. Jakarta: JHPIEGO; 2002.

10. Departeman Kesehatan Republik Indonesia. Etika dan Kode Etik Kebidanan. Jakarta2002.

11. Wiknjosastro H. Ilmu Kebidanan. Jakarta: Yayasan Bina Pustaka Sarwono Prawirohardjo; 2005. 
12. Pusdiknakes. Asuhan Kebidanan. Jakarta: JHPIEGO; 2001.

13. Badan Litbang Depkes Republik Idonesia. Survei Kesehatan Rumah Tangga (SKRT). Jakarta2001.

14. Anderson. Behavior Model of Fainment Use of Health Service 1998

15. Siagian. Sondang. Teori Motivasi dan Aplikasinya. Jakarta: PT Rineka Cipta; 1995.

16. Notoatmodjo. Soekidjo. Pendidikan Kesehatan Masyarakat. Jakarta: Rineka Cipta; 1997.

17. Zeithaml V. Parasuraman A dan Berry L. Delivering Quality Service, Balancing Customer Perceptions and Expectations. New York, USA: by The Free Press, Macmillan, Inc; 1990. 